Elena A. Polyakova, Dr. of Historical Sciences, Associate Professor Altai State Institute of Culture, Barnaul Law Institute of the Ministry of Internal Affairs of the Russian Federation (Barnaul, Russia) elena2873@mail.ru

\title{
HERITAGE - KEY LINE OF CONCEPT-BASED DEVELOPMENT OF EDUCATIONAL ACTIVITIES OF A MUSEUM
}

\begin{abstract}
As an institution of social memory museum is focused at recording, scientific studying, and protecting objects of the mankind's historical, cultural, and natural heritage. A social need in learning heritage for building up and correcting worldviews of a personality and social groups entailed a shift in priorities of museum work towards educative activities and defined a way of development of a museum as an educative form of culture. Active processes of cultural standardization that run in the global scale triggered a problem in upbringing a personality's sustainable ethnic and cultural identity; a museum can make a sizeable contribution to solving this problem through disclosing historical and cultural socially significant senses. However, on the author's opinion strong tendency to exploitation of museum areas for events with non-museum directivity (for recreational activity or entertaining) has negative impact on quality of educational activities of a museum. Also, some theoretical issues of popularization of historical, cultural, and natural heritage by means of museum work are considered in the article.

Key words: a museum, historical and cultural heritage, natural heritage, essential functions of a museum, educational activities of a museum, educational form of culture, museum communication, representation of cultural heritage through museum work, recreational activities of a museum.
\end{abstract}

УДК 330.131.5:338.484.2(470+571)

DOI: 10.32340/2414-9101-2019-2-49-53

Ю. С. Путрик, доктор исторических наук Центр социокультурных и туристских программ Российского научно-исследовательского института культурного и природного наследия им. Д. С. Лихачёва (Москва, Россия) putrik@list.ru

\section{К ВОПРОСУ ОБ ИЗМЕРЕНИИ, ОЦЕНКЕ И ЭФФЕКТИВНОМ ИСПОЛЬЗОВАНИИ ИСТОРИКО-КУЛЬТУРНОГО ПОТЕНЦИАЛА НА РЕГИОНАЛЬНОМ УРОВНЕ}

Аннотация. Изложен авторский взгляд на узловые проблемы измерения историко-культурного и туристско-рекреационного потенциала провинциальных территорий современной России, охарактеризованы трудности выработки методики объективной оценки уровня социально-экономической эффективности эксплуатации отечественных объектов культурного и природного наследия, расположенных в российских регионах; указанные вопросы приобретают особую актуальность в контексте реализации государственной стратегии пространственного развития страны, предусматривающей устранение грубых диспропорций в социально-экономическом развитии регионов. Подчёркнуты преимущества применения технологии туристического «брендирования» территории, позволяющей сформировать привлекательный для туристов, инвесторов и бюджетных субсидий образ объекта историко-культурного или природного наследия. Охарактеризованы предпосылки к формированию новых подходов к вопросам квантификации ключевых характеристик историко-культурного потенциала территорий.

Ключевые слова: объекты историко-культурного наследия России, природное наследие России, стратегия пространственного развития России, сочиально-экономический эффект туристскорекреационной эксплуатации объектов культурного наследия, инфраструктура туризма, брендирование территории, комплексная оченка историко-культурного и природного потенциала России, транспортная доступность объектов историко-культурного и природного наследия. 
Согласно утверждённым в 2014 г. Указом Президента Российской Федерации Основам государственной культурной политики в нашей стране «...культура России - такое же её достояние, как и природные богатства. В современном мире культура становится значимым ресурсом социальноэкономического развития, позволяющим обеспечить лидирующее положение нашей страны в мире» [1]. Заметим, что природные богатства и социально-экономические ресурсы измеряются и оцениваются в количественных и качественных показателях, т. е. подлежат измерению и оценке. Таким образом, актуализируются, соответственно, вопросы измерения и оценки культурного, т. е. историкокультурного цивилизационного потенциала страны и отдельных регионов и сегодня, благодаря активно развивающимся технологиям цифровизации, открываются широкие возможности для разработки конкретных механизмов выявления и продвижения ценностного содержания культурных проектов, перехода к работе по измерению цивилизационных ценностей и последующему использованию результатов этих измерений в практической плоскости для решения задач по повышению экономической и социальной эффективности использования наследия с учётом уровня цивилизационной идентичности регионов РФ. Речь идёт, прежде всего, о материальных объектах культурного наследия, как материальных носителях коллективной исторической памяти, которые аккумулируют в себе колоссальную информацию об истории, традициях и культуре нашего народа, служат в буквальном смысле материальной платформой, материальным фундаментом российской цивилизационной идентичности. Объекты культурного наследия, являясь материальной основой культурной идентичности российской нации, приобретают особую актуальность и практический смысл не только в современных условиях тотальной информационной войны за возможность устойчивого и безопасного социально-экономического развития российского государства, но и на региональном уровне в условиях возрастающей конкуренции между субъектами Российской Федерации по целому комплексу направлений продвижения своих возможностей в разных сферах экономической и общественной деятельности.

Действительно, о несметных богатствах историко-культурного наследия нашей страны мы все знаем, гордимся этим богатством, широко обращаемся к нему в культурных-просветительских, образовательных, воспитательных, туристских и других общественно значимых целях. Однако когда поднимается вопрос о социально-экономической эффективности, то ограничиваемся, как правило, весьма общими оценками на качественном уровне. Более точно определить социально-экономический эффект от использования наследия, в т. ч. в количественных показателях станет возможным, когда мы научимся измерять в количественных и качественных показателях материальную компоненту культурно-исторического и природного наследия. А это, как известно, прежде всего памятники истории, архитектуры, искусства, археологии, исторические города, музеи, музеи-заповедники и музеиусадьбы и другие историко-культурные объекты, а также природные объекты - национальные парки, памятники природы, заповедники, т. е. особо охраняемые природные территории. Совокупность этих объектов, их сочетания в том или ином регионе как раз и составляет тот самый историко-культурный и природный ресурс не только социокультурного, но и пространственного развития.

Говоря, кстати, о пространственном развитии, заметим, что сегодня уже на уровне Правительства РФ реализуется осознание колоссального пространства России - самой большой по площади страны мира - как ресурса социально-экономического развития. Так, в последние несколько лет идея пространственного развития России активно продвигается на всех уровнях. В Федеральном законе № 172 от 28.06.2014 «О стратегическом планировании в Российской Федерации» появилась статья 20, которая так и называется «Стратегия пространственного развития» [2]. В августе 2015 г. принято Постановление Правительства России «О порядке разработки и утверждения стратегии пространственного развития» [3]. В 2016 году Минэкономразвития представил проект Концепции пространственного развития России до 2030 г. и, наконец, в феврале 2019 г. распоряжением Правительства Российской Федерации была утверждена Стратегия пространственного развития Российской Федерации на период до 2025 года [4].

В контексте темы данной статьи важно отметить, что в числе важнейших принципов пространственного развития в стратегии продекларировано не только сохранение природного и историкокультурного наследия, но и их активное туристско-рекреационное использование в сочетании с по- 
вышением транспортной доступности данных объектов и включением в этом процесс мест бытования народных художественных промыслов.

Таким образом, вопросы выявления объёмов и оценки региональных совокупностей материальных компонентов культурного и природного наследия ещё больше актуализируются. Проще говоря, пришло время провести, наконец-то, комплексную оценку историко-культурного и природного цивилизационного потенциала страны и её отдельных регионов. Для этого сегодня сложились все необходимые предпосылки, такие как

- официально признанный и институализированный цивилизационно-ценностный подход;

- реализуемая стратегия пространственного развития;

- новые возможности для работы с цифровым контентом, которые открылись в последнее время благодаря развитию цифровизации в сфере культуры.

В данном случае речь идёт о масштабном проекте, реализуемом Министерством культуры, по созданию в электронном виде Государственного реестра объектов культурного наследия народов Российской Федерации, который сегодня уже доступен на портале открытых данных Министерства культуры и в который на данный момент внесено более $80 \%$ всего массива памятников истории, культуры, искусства и археологии, который в целом включает более 180 тысяч таких объектов. Однако, как было указано выше, материальная основа культурно-исторического и природного наследия состоит не только из памятников, сюда же входят и площадные объекты, такие, как музеизаповедники, исторические поселения, национальные парки, включающие культурные ландшафты, а также памятники природы. Поэтому для реализации «принципа измеряемости» возникает задача обеспечения сопоставимости и унификации данных об объектах наследия и введения соответствующих индексов и эквивалентов. Решение этой задачи лежит в плоскости определения сопоставимости показателей территориального распределения статуированных цивилизационных ценностей, в том числе и для последующей картографической интерпретации. Под статуированными объектами в данном случае подразумеваются объекты наследия федерального значения.

Практическая направленность данного направления исследований связана с проблемами брендирования территории. В этой связи отметим, что в современных условиях роль брендирования территории, как привлекательного объекта для туристов, инвесторов и бюджетных субсидий неизмеримо возрастает. Процесс брендирования происходит активно и к настоящему времени получил определенное практическое воплощение в основном по отношению к конкретным административным центрам и другим большим и малым населённым пунктам. Однако по отношению к обширным территориям, каковыми являются территории субъектов РФ сложился определённый вакуум, т. е. брендирование конкретных регионов (субъектов РФ) в целом не получило достаточного развития и не используется в должной мере для повышения привлекательности субъектов РФ.

Говоря о социально-экономической эффективности использования наследия, необходимо иметь в виду, что, хотя измерение и оценка историко-культурного потенциала территории - это очень важный, но только первый этап процесса получения социально-экономического эффекта от использования наследия. На региональном же и местном уровнях нужна, безусловно, инфраструктура, обеспечивающая доступность объектов, а также комфортное пребывание и восприятие объекта. И этого тоже недостаточно. Мы имеем сегодня немало примеров, когда в рамках проектов туристских кластеров создана туристская инфраструктура, не покреплённая содержательным пребыванием, и поэтому такие кластеры становятся малопосещаемыми, а дорогостоящие объекты имеют шанс превратиться в никому не нужные руины. Поэтому, если говорить о туризме, то необходима комфортная туристская среда, методика и практика создания которой у нас ещё не отработана. И, конечно же, необходимы постоянные мероприятия, информация и программы как результат систематической работы по социокультурному проектированию с вовлечением местных жителей, которые привлекали бы туристов и делали их пребывание в данной дестинации интересным и содержательным с точки зрения познания истории и культуры места их пребывания.

Отмечая ключевую роль социокультурного проектирования при использовании объектов культурного наследия в стратегии пространственного развития, хотелось бы отметить такое явление, как расширяющаяся центробежная интеллектуальная миграция из больших городов в малые исторические города и сельскую местность, которая расширяется и становится все более важным фактором 
пространственного развития. Это миграция людей, привносящих в российскую провинцию, в отличие от традиционных дауншифтеров, креатив и инновации и новые социокультурные проекты, направленные на сохранение и эффективное использование культурного и природного наследия в рамках стратегии пространственного развития России.

К настоящему времени тенденция переезда профессионалов из мегаполисов в малые исторические города и сельскую местность, как в место постоянного проживания и деятельности, уже сложилась и приобрела пусть пока ещё не масштабный, но устойчивый характер. Мотивы современной центробежной миграции постоянно расширяются и подкрепляются улучшающейся инфраструктурой, транспортной доступностью и современными информационными коммуникациями, позволяющими, не выпадая из своей профессиональной среды, эффективно заниматься коммерческой, профессиональной, творческой, общественной и благотворительной деятельностью. Однако эта деятельность остаётся малоизученной и поэтому целенаправленно не используется в качестве инструмента социально-экономического развития территорий. И эта тенденция нуждается, конечно же, в государственной поддержке и стимулировании и в русле стратегии пространственного развития.

Сегодня уже появляется опыт активного участия местного населения и тех же центробежных интеллектуальных мигрантов в формировании привлекательной и комфортной туристской среды в отдельных малых городах при поддержке местной администрации, но такие примеры единичны и какого-то устойчивого тренда в этом направлении пока не сложилось, и здесь кроются, безусловно, колоссальные резервы. То есть, пока мы констатируем дефицит креативной инициативы резидентов. А там, где такие инициативы начинают проявляться и несут с собой прогрессивные изменения в социокультурной структуре какого-нибудь небольшого населённого пункта, та же местная администрация часто оставляет без поддержки новые начинания, идущие «снизу». Яркой иллюстрацией такой ситуации может служить пример острова Шикотан в Сахалинской области, когда предпринимательская структура начала реализовывать масштабный диверсификационный проект по созданию на острове современной социокультурной и туристской инфраструктуры с торговым центром, туркомпанией, гостиницей, бассейном и другими объектами, при этом натыкясь на ожесточённое противостояние местных властей [5]. Возникновение таких ситуаций следует, видимо, рассматривать как сигнал к кардинальному пересмотру критериев оценки результативности деятельности областных и муниципальных администраций по показателям их социокультурной деятельности.

Таким образом, в условиях современной информационной среды, когда воздействие постоянно увеличивающихся и часто противоречивых информационных потоков осложняет восприятие и понимание цивилизационных ценностей, резко возрастает роль и значимость материальной константы историко-культурного наследия не только как неопровержимого аргумента цивилизационной принадлежности, но и её всестороннего использования как фактора повышения известности и привлекательности регионов и местностей за счёт создания благоприятной социокультурной и туристской среды.

\section{Список литературы}

1. Об утверждении Основ государственной культурной политики : указ Президента Российской Федерации от 24.12.2014 г. № 808. - Текст : электронный // Консорциум «Кодекс», электронный фонд правовой и нормативно-технической информации : сайт. - URL: http://docs.cntd.ru/document/420242192 (дата обращения: 11.02.2019).

2. О стратегическом планировании в Российской Федерации : федеральный закон от 28.06.2014 г. № 172Ф3. - Текст : электронный // Консорциум «Кодекс», электронный фонд правовой и нормативно-технической информации : сайт. - URL: http://docs.cntd.ru/document/420204138 (дата обращения: 10.02.2019).

3. О содержании, составе, порядке разработки и утверждения стратегии пространственного развития Российской Федерации, а также о порядке осуществления мониторинга и контроля её реализации : постановление Правительства Российской Федерации от 20.08.2015 г. № 870. - Текст : электронный // Консорциум «Кодекс», электронный фонд правовой и нормативно-технической информации : сайт. - URL: http://docs.cntd.ru/document/420296976 (дата обращения: 12.01.2019).

4. Стратегия пространственного развития Российской Федерации на период до 2025 года : распоряжение Правительства Российской Федерации от 13.02.2019 г. № 207-p. - Текст : электронный // Консорциум «Кодекс», электронный фонд правовой и нормативно-технической информации : сайт. - URL: http://docs.cntd.ru/document/550971585 (дата обращения: 15.02.2019). 
5. Азар, И. В. «Тут не ходят в белых носках»: самый полный путеводитель Ильи Азара по Шикотану. Текст : электронный // Новая газета : [сайт]. - 2019. - 6 мая. - URL: https://www.novayagazeta.ru/articles/2019/ 05/06/80442-tut-ne-hodyat-v-belyh-noskah (дата обращения: 07.05.2019).

Yurii S. Putrik, Dr. of Historical Sciences Dmitri Likhachyov Russian Cultural and Natural Heritage Research Institute, Social, Cultural, and Touristic Programs Department (Moscow, Russia) putrik@list.ru

\section{REVISITING MEASUREMENT, ASSESSMENT, AND EFFECTIVE USE OF HISTORICAL AND CULTURAL POTENTIAL AT A REGIONAL LEVEL}

Abstract. The paper discloses the author's views on the key problems in measurement of touristic potential of historical, cultural, and natural heritage from the Russian areas, on difficulties related with elaboration of methodic for assessment of a level of social and cultural resulting character of using domestic items of cultural and natural heritage that located in Russian regions; these questions get especial sharpness within the context of implementation of the state Spatial Development Strategy of Russia which aimed at neutralization of rough disproportion in social and economic development of the today's Russian territories. The author stresses out advantages that technologies of touristic brending zones in building up attractive image of an area with objects from the category of historical, cultural, and natural heritage for tourists, capital providers, and budgetary subsides. Also, the paper describes factors create of a new approach to the questions of quantification of the key characteristics of historical and cultural capacity of an area.

Key words: objects of historical and cultural heritage of Russia, natural heritage of Russia, Spatial Development Strategy of Russia, social and economic resulting character of use of objects of cultural heritage in touristic sphere, supporting economic structure for tourism, creation of a brand for an area, complex assessment of historical, cultural, and natural value of Russia, vehicle access to objects of historical, cultural, and natural heritage. 